


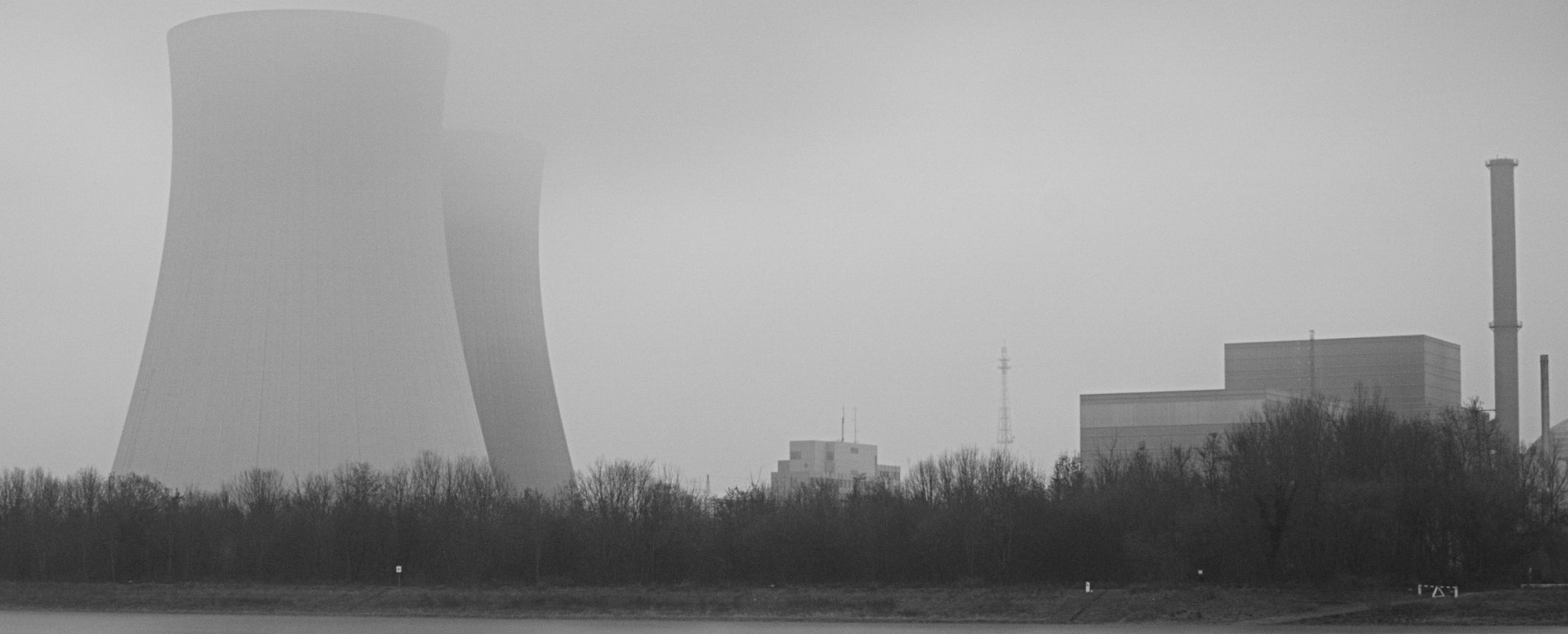


finding

Phasing out a risky

technology: An endgame

problem in German

nuclear power plants?

Markus Schöbel, Ralph Hertwig, \& Jörg Rieskamp

abstract

Germany has twice decided to abandon nuclear energy. The first time, it set somewhat dynamic shutdown dates for plants before changing course. The second time, it set fixed shutdown dates. Game theory holds that awareness of shutdown dates may lead to endgame behavior, in which people at all levels of the industry behave more self-interestedly, thus potentially jeopardizing public safety, as the end dates approach. We examine whether such behavior is occurring in Germany by drawing on three sources of evidence: the public record, the frequencies of reportable safety-related events, and experimental data. The findings are inconclusive but suggest that the concerns merit consideration by policymakers in Germany or wherever policies need to be designed for the phaseout of dying industries. Counterintuitively, a policy designed to increase public safety may inadvertently create novel risks if it does not attend closely enough to the behavioral factors involved in its implementation.

Schöbel, M., Hertwig, R., \& Rieskamp, J. (2017). Phasing out a risky technology: An endgame problem in German nuclear power plants? Behavioral Science \& Policy, 3(2), $41-54$. 


\section{Core Findings}

What is the issue? Decommissioning high reliability organizations such as nuclear power utilities carries risks of endgame behavior. With a finite horizon for operation, it is possible that agents will behave self-interestedly and shift behavior and investment away from safety. This, in turn, may increase the frequency of events with a higher safety significance as the shutdown date of a plant approaches.

How can you act? Selected recommendations include:

1) Increasing data transparency in plant operations so that endgame risks can be assessed

2) Establishing innovative engineering programs focused on the decommissioning and dismantling of aging nuclear power plants

Who should take the lead?

Behavioral science researchers, and policymakers in energy. $\mathrm{n}$ the wake of the Fukushima Daiichi nuclear accident in Japan in March 2011, the German government decided-once again-to phase out the country's use of nuclear energy. It was the second time the nation had opted to abandon nuclear energy. In 2001, the government had assigned each nuclear power plant a residual electricity output-a total amount of electricity it was to produce in the years ahead; ${ }^{1}$ once that total was reached, the plant was to be taken off the grid. In October 2010, the government, now with different leadership in place, reversed this plan, deciding to allow the country's 17 nuclear plants to operate until at least 2036. But in June 2011, mindful of the public's concerns about nuclear safety after the Fukushima disaster and the recommendations of an expert commission, the government shut down eight plants immediately and specified shutdown dates for the remaining nine. These appointed dates ranged from 2015 to 2022 and cannot be exceeded. In other words, if anything disrupts energy production for a time (such as planned outages and unexpected events), the close date will not be extended to compensate for the hiatus. ${ }^{2}$ This fresh commitment to closing down nuclear power plants was the start of Germany's Energiewende, or energy transition-its shift away from nuclear power and fossil fuels to renewable energies.

The 2011 phaseout policy was established to protect Germany from the risks of nuclear energy production in the long term. We argue that in the short term, the design of the phaseout scenario can have unintended consequences for nuclear safety. We base our argument in part on studies of game theory. Specifically, working in or managing a plant that is scheduled to be shut down on a specific date is not unlike participating in a repeated game that will end in the near future. ${ }^{3-5}$ Empirical evidence from finitely repeated games predicts an increase in endgame behavior-a shift toward selfinterested behavior as the game's conclusion draws near. In the case of Germany's nuclear power plants, this could mean that the industry or individual employees change their behavior as the shutdown date of each plant approaches, which could affect public safety.

\section{Endgame Behavior in Finitely Repeated Games}

Generally speaking, game theory considers conflict and cooperation between rational decisionmakers. Theorists analyze these interactions across a wide range of games, with different games representing different properties of realworld interactions. One important property is the time horizon: games can be one-shot or repeated. A repeated game with a finite time horizon is played a known, specific number of times. There are also indefinitely repeated games, in which the players do not know when the repetition will stop; that is, there is no preordained number of repetitions. In this article, though, we focus mainly on finite time horizons, because Germany's 2011 phaseout plan calls for reactors to be shut down on fixed dates.

Game theory holds that people who play finite games will behave the same way regardless of whether the game is played once or multiple times. In finitely repeated games, optimal behavior is determined by backward induction: players anticipate their optimal moves for the last period (that is, the last round) of the game, then for the second-to-last period, and continue the process backward to the first period. In theory, if a one-period game is repeated finitely, then the game-theoretical prediction for the one-period game holds for every period of the repeated game. For instance, in a social dilemma situation, in which a person can contribute to the general good or else behave opportunistically, game theory holds that a self-interested player should not contribute to a public good in either a one-period game or a finitely repeated game. Experimental economists have shown, however, that people do not strictly conform to this prediction. In fact, people initially cooperate in finitely repeated social dilemma games, but then endgame behavior takes over: cooperation typically declines and free riding increases over the course of the game. ${ }^{5-9}$

We suggest, therefore, that phaseout policies with predetermined shutdown dates carry the risk of fostering detrimental endgame behavior in any dying high-reliability organization-one that is prone to accidents unless great vigilance is maintained. In this context, we think of 
endgame behavior as a multilevel phenomenon, with safety risks stemming from self-interested behavior occurring at the level of the individual on up to the level of organizations.

To the best of our knowledge, no previous research has examined the potential risks of endgame behavior in high-reliability industries faced with organizational demise. At this point, the possibility that Germany's decision to phase out nuclear power is fostering endgame behavior can be analyzed only (a) conceptually (by drawing on the public record), (b) empirically (by analyzing the scant data available, that is, the frequency of reportable safety events), and (c) experimentally (by systematically manipulating the impact of simulated phaseout strategies on individual decisionmaking). In this article, we pursue all three routes.

\section{Conceptual Observations: The Public Record}

Which conditions may undermine nuclear safety? These days, experts in industrial safety favor a systems approach to managing risks in high-reliability organizations. ${ }^{10-12}$ They model the critical components of risk management across a hierarchy of levels-from legislation to government agencies, industry associations, utility and plant management, and single-plant employees. People and organizations at higher levels impose constraints on the activities of the people and organizations at subordinate levels. Endgame behavior, manifested as a shift toward self-interested behavior, ${ }^{6}$ may occur at any of these levels and wherever the levels interact.

At the top levels, an impending shutdown may change the interactions between utility companies and government agencies, reducing the companies' incentives to meet regulatory demands. The public record catalogs several key events that may be interpreted as signs of deterioration in the trust and collaborative relationships between companies and the government.

For instance, after a few years in which profits from nuclear and fossil fuel power generation slumped, ${ }^{13}$ in 2014 , the utilities proposed that ownership of all nuclear power plants and the associated risks should be transferred to a public trust. The trust would be responsible for operating the plants until they wound down and then for their decommissioning and dismantling, as well as for the final disposal of radioactive waste. In other words, the trust would free the utilities from any liability. In exchange, the utilities would contribute around $€ 30$ billion in reserves that they had been required to build up over time to cover the costs of dismantling plants and managing nuclear waste. ${ }^{14}$ In 2016 , a federal government commission set up to review the financing of the nuclear phaseout issued a final report rejecting this proposal and instead recommending a division of labor: companies would retain the responsibility and unlimited liability for operating, decommissioning, and dismantling plants and packing radioactive waste, whereas the government would take responsibility for the waste's intermediate storage and for the operation of the final repositories. ${ }^{15}$ In late June 2017, Germany's economy ministry and the country's four utility companies formally agreed to that proposal, and in July 2017 the companies paid $€ 24.1$ billion into the newly created "Fund for Nuclear Waste Management."

In another sign of stress between the utilities and the government, in 2014, Germany's biggest utility company, E.ON, announced plans to split into two companies, one focusing on nuclear and fossil fuel and the other on renewable energies. According to media reports, "many observers took E.ON's decision to hive off the fossil-fuel and nuclear-generation business as the creation of a kind of 'bad utility' - like the 'bad banks' created to house toxic assets after the financial crisis." ${ }^{16}$ However, once the German government proposed making companies permanently liable for the costs of dismantling reactors, E.ON canceled its plans to spin off its German (although not its Swedish) nuclear power plants.

Furthermore, the German utilities E.ON and RWE and the Swedish utility Vattenfall sued the German government over the legality of the 2011 nuclear phaseout. The case reached the Federal Constitutional Court (Germany's 


\section{"endgame behavior could be manifested as decreasing efforts by industry to maintain the skills and motivation of its workforce"}

highest court) in 2016, with the utilities accusing the German state of expropriating their atomic plants without paying compensation. ${ }^{17}$ In December 2016, the court mostly rejected their claims, deeming the law for a nuclear phaseout "mostly compatible with Germany's constitution." ${ }^{18}$ In another lawsuit, though, the court ruled in June 2017 that a nuclear fuel tax imposed on energy utilities in 2011 was unconstitutional, which, in turn, allowed nuclear utilities to claim billions of euros in refunded taxes. Relatedly, Vattenfall has filed a request for arbitration against Germany at the International Centre for Settlement of Investment Disputes. According to Germany's Federal Ministry for Economic Affairs and Energy, Vattenfall is asking for $€ 4.7$ billion ( $\$ 6$ billion) in compensation for the nuclear shutdown. ${ }^{19}$

Aside from what media observers describe as a "bruising confrontation" ${ }^{17}$ between utilities and the German government in the courts, endgame behavior could be manifested as decreasing efforts by industry to maintain the skills and motivation of its workforce and, by extension, the level of nuclear safety. As early as 2012, the German Reactor Safety Commission (RSK), which gives nuclear safety advice to the Federal Ministry for the Environment, Nature Conservation and Nuclear Safety, published a memorandum warning of the loss of know-how and motivation among plant employees. ${ }^{20}$ Specifically, the commission exhorted management not to give the workforce the impression that it is viewed as a somewhat difficult and marginalized group and to offer employees ways to continue their careers. At the end of 2016, the RSK reiterated its concerns from the 2012 memorandum. ${ }^{21}$ After consulting representatives of contractor organizations, agencies, regulators, and utility companies from the German nuclear industry, the RSK recommended that these entities should implement change-management measures (such as monitoring, evaluating, and supporting processes of change) and establish procedures for documenting and monitoring the competencies of all employees.

The RSK recommendations were made in response to past developments in the German energy supply market and to concerns about the future effects of the phaseout decision on the plants that are still operating. All utilities have implemented far-reaching cost-cutting measures in response to the 2011 phaseout decision. For instance, Areva, one of the largest on-site contractors in the German nuclear power industry, with several thousand employees, has reduced staff due to a site closure. ${ }^{22}$ For its part, RWE attempted to negotiate with the union to get a $25 \%$ wage cut for all employees in the power generation division, ${ }^{23}$ and E.ON's nuclear unit has recently announced that it will cut at least half of its workforce by $2026 .{ }^{24}$

The utilities' publicly available financial reports do not detail exactly where costs have been cut. Therefore, the extent to which utilities continue to invest in technical system upgrades, continuous training, safety culture initiatives, and on-site contractors is unknown. It is unlikely, however, that new investments in complex technical safety upgrades, which can take years to implement, are in the works. By the terms of the 2011 nuclear power phaseout plan, the plant outages that would be required to enable the installation of safety upgrades would reduce plants' remaining operation times, which would make safety investments increasingly difficult to justify on purely economic grounds. ${ }^{25}$ Even if investments are still made and jobs are not cut, a relative decline in expertise will be inevitable, because the industry is losing its ability to attract highly qualified new workers. Indeed, German universities have a dearth of new students in nuclear safety engineering, even though such knowledge will be needed to operate the intermediate and final repositories. Relatedly, reports indicate that the industry has reduced or ended 
its support for nuclear engineering research at universities. ${ }^{26}$

These signs of the utilities' disengagementalong with the extensive media coverage of the industry's financial difficulties and pending demise-have no doubt affected plant employees. Although no data are publicly available, it seems reasonable to suspect that a brain drain-the emigration of highly marketable employees-is leaving behind a negatively selected group to oversee the plant's final operation and transition to retirement. Research suggests that job insecurity, as is faced by this group, is associated with declining safety knowledge and dwindling motivation to comply with safety policies, which may, in turn, lead to more accidents and to injuries in the workplace. ${ }^{27}$

Even though the situation in Germany seems to make the unraveling of safety standards and behaviors more likely than before, a strong organizational safety climate could potentially attenuate the threat. ${ }^{28}$ Yet even relatively subtle psychological responses to pending organizational demise can pose a risk. According to a thesis known as the threat-rigidity hypothesis, individuals and groups tend to behave rigidly in dying organizations. ${ }^{29}$ Rigid behavior-in terms of less mindful information processing, less vigilance and attention, unwillingness to take responsibility and to learn, and work-torule activity-can undermine important safety behaviors (such as mindful and questioning behavior), ${ }^{30,31}$ especially if the organization has a weak safety climate.

\section{Frequencies of Reportable Events}

Beyond the trends described above, are there quantifiable empirical indications of an endgame dynamic in the German nuclear power industry? Such indicators as near-miss reports or management audits of single plants are not publicly available and therefore cannot be investigated. We can, however, examine one important and publicly available indicator of nuclear plant safety: the frequency of reportable events. In Germany, the Nuclear Safety Officer and Reporting Ordinance obliges nuclear power facilities to report all events of "higher safety significance"-such as malfunctions, unexpected outages, and incidents known as process safety accidents-to the Incident Registration Centre of the Federal Office for the Safety of Nuclear Waste Management. ${ }^{32}$

The endgame hypothesis suggests that the frequency of reportable events in German nuclear power plants will increase as the shutdown date of a plant approaches. Several factors complicate the analysis of whether this suggestion is correct, however. First, there is no firm theoretical ground for predicting the precise moment at which the endgame starts (that is, the onset of a potential endgame). Second, different players within the same company may experience and perceive the terminal stages of a dying industry differently. For instance, the management of a utility is accountable for all of its plants, and this responsibility extends beyond the closure of a single plant. In contrast, the employees of that plant are immediately affected by the utility's restructuring plans.

Notwithstanding these difficulties, one way to probe potential endgame effects in German nuclear power plants is by contrasting the annual frequencies of reportable events before and after the 2011 phaseout decision. To this end, we determined the average frequency of events occurring five years before and five years after the 2011 decision at the eight plants then still operating (using the annual reports from 2006 to 2016 of the Incident Registration Centre of the Federal Office for the Safety of Nuclear Waste Management). Contrary to the endgame hypothesis, the average frequencies of reportable events for these plants were relatively stable within the five-year period before and after the 2011 decision: the half-year means were 2.40 and 2.35, respectively (see Figure $1 \mathrm{~A}$; see also the frequencies of reportable events listed separately for individual plants in the Supplemental Material).

We wondered whether the pattern was similar after the 2001 shutdown decision. In that case, Chancellor Schröder and representatives of the German nuclear industry signed an agreement to phase out nuclear energy over the next 20

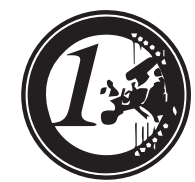

$€ 24.1$ billion

Contribution cost to German energy utilities for a state fund to store nuclear waste and operate final repositories

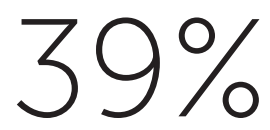

Increase in average frequency of reportable events at Germany's nuclear plants after the 2001 shutdown decision

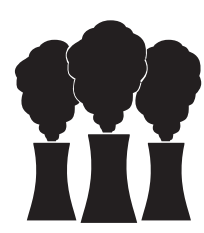

234

Number of operating nuclear reactors worldwide that are more than 30 years old 
years (in what become known as the nuclear consensus). The agreement became law in April 2002. Recall that, in contrast to the 2011 phaseout decision, the shutdown dates were not fixed; plants would be taken off the grid when their assigned residual electricity output was reached. The termination dates could vary because output allowances could be transferred from one plant to another and because unplanned and planned outages (such as for maintenance work or the technical upgrading of plants) would delay the final shutdowns. It was nonetheless clear that as they approached the allotted electricity output, the shutdown day came closer and the probability of termination increased. When the probability of termination increases over time, game theory predicts endgame behavior. Although no one knows exactly when the termination probability will cross a critical threshold-after which, for instance, safety investments are no longer paying out-it is likely that at some point, this threshold will be reached; therefore, endgame behavior should be expected.

As in the first analysis, we examined the average frequencies of reportable events during fiveyear windows before and after the 2001 decision (using the annual reports from 1996 to 2006 obtained from the Incident Registration Centre of the Federal Office for the Safety of Nuclear Waste Management). Figure 1B shows that during the five years directly after the 2001 decision, the average half-year frequency of reportable events of the 17 operational plants increased by $39 \%$, from 2.79 to 3.87 events (in an exact two-tailed Wilcoxon signed rank test, $W=16.5, p=.003$ ). (See note A.) Specifically, the number of events increased in 15 of the 17 plants.

In other words, we found an increase in the annual frequency of reportable events in the wake of the 2001 but not the 2011 phaseout decision. We do not have a clear explanation for the difference, but we can see a number of possible contributing factors. One is that the politics surrounding the 2001 situation makes it hard to know when the endgame is most likely to have commenced. Perhaps we looked at the wrong time interval. As mentioned earlier, there is, in any case, no firm theoretical ground for predicting the timing of the onset of endgame behavior. Also, although the nuclear power legislation did not become law until 2002, the end of nuclear energy generation in Germany was already predictable at the time of the 1998 elections, which saw victories by the Green Party and the Social Democrats. The agreement between the German government and the energy companies was reached in 2000 and endorsed by both parties in 2001. This more prolonged decision time line, combined with the different phaseout architectures of the 2001 and 2011 plans, also means that one cannot draw any firm conclusions from the 2001 case about when endgame behavior, as manifested by higher frequencies of reportable events, is likely to start in the nuclear power plants that are operating in Germany today.

We can envision a couple of additional reasons for the different outcomes. The two phaseout decisions were caused by incommensurable events: the Greens and Social Democrats winning the German federal election versus the Fukushima Daiichi nuclear disaster. The nuclear disaster, unlike the election victory, may have caused the nuclear power industry and its employees to be on full alert, even more than usual. Also, the phaseout decisions could have differed in their influence on the plants' reporting thresholds. Plant managers have some freedom in deciding whether and when an event is reported, and utilities may exploit this wiggle room to different extents. Because the 2001 decision allowed plants to extend their operating time if they had production outages, the plants may have been more willing to report events and take the time needed to address them. But for today's plants, any production outages (such as those for events that require technical upgrading to fix or a prolonged and deepened root-cause analysis) and associated financial losses cannot be recouped in the future. This constraint may result in a higher threshold for what constitutes a reportable event. Admittedly, all these explanations are speculative.

Can the different outcomes be better understood by considering what is happening in 
Figure 1. Average frequencies of reportable events (per half year) five years before $\&$ after (A) the 2011 phaseout decision (for the eight operating plants) \& (B) the 2001 phaseout decision (for the 17 operating plants)
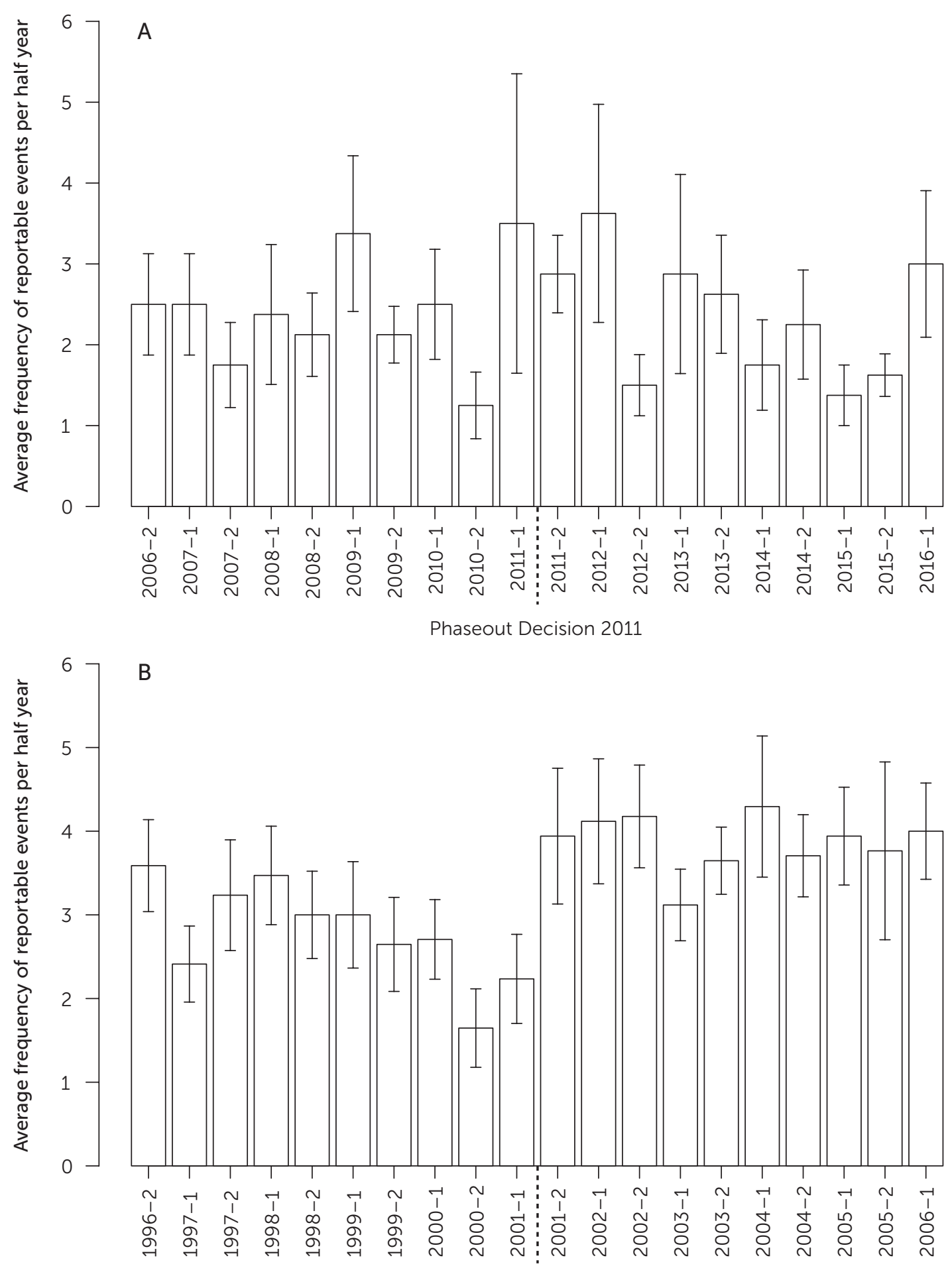

Phaseout Decision 2001

Note. Reportable events meet the German Nuclear Safety Officer and Reporting Ordinance criteria for higher safety significance, such as malfunctions, unexpected outages, or process safety incidents (Federal Office for the Safety of Nuclear Waste

Management, 2016). Error bars represent an interval of \pm 1 standard error of the mean, the extent of deviation from the mean. 


\section{"there is reason to worry that phaseout decisions in a dying high-reliability industry could carry an increased risk of detrimental endgame effects"}

other countries? Germany, after all, is not the only country in which nuclear power is being phased out. Our study of nuclear phaseout policies in other countries, however, has identified only one case that seems comparable with the German situation, involving a substantial delay between a political decision and the actual industrial shutdown: Sweden. In 1997, long after a 1980 referendum in which the majority of the Swedish population voted to phase out nuclear power, the government passed phaseout legislation. ${ }^{33}$ On the basis of this phaseout act, the Swedish government decided that the Barsebäck 1 reactor would be closed in June 1998, and the Barsebäck 2 reactor would be shut down in July 2001. After the Swedish supreme administrative court rejected an appeal against the decision submitted by the plant's owner in June 1999, Barsebäck 1 was permanently shut down in November 1999. Barsebäck 2, in contrast, was not shut down until May 2005, after repeated postponements of the shutdown date due to a lack of renewable energy to replace its output. ${ }^{34}$ It is interesting that in 2004, shortly before its closure, Barsebäck 2 reached an all-time peak in production. At the same time, reportable events at Barsebäck 2 increased from 21 in 2002 to 48 in 2004 (see Figure S3 in the Supplemental Material). Final bursts of productivity have also been reported for conventional organizations facing terminal shutdown. ${ }^{35}$ The increase of reportable events may be consistent with the extended endgame period of Barsebäck 2, at the expense of a usually strong emphasis on safety. This single case, however, defies any general conclusions.

To conclude, the data on reportable events before and after Germany's phaseout decisions paint a mixed picture. Nevertheless, the findings for the operational plants after the 2001 decision and for the operational Swedish Barsebäck 2 reactor suggest that there is reason to worry that phaseout decisions in a dying highreliability industry could carry an increased risk of detrimental endgame effects. We emphasize that the case is not yet strong, however, and that the specifics of the situations could be important. Some plants contributed more to the increase in reportable events than others, for instance (see the Supplemental Material). Moreover, the data we examined are not free of noise and bias. For instance, the date of reporting can deviate from the date of the event, and single plants may have varying reporting thresholds. ${ }^{36}$

\section{Experimental Evidence of Endgame Effects on Safety- Relevant Investments}

Experimental results have successfully informed a wide range of public policy and institutional design decisions, such as auctions for electric power in California ${ }^{37}$ and the British 3G telecom licenses auction. ${ }^{38}$ Against this background, we investigated the potential impact of endgame effects on safety in controlled experimental studies simulating two phaseout strategies. One strategy simulated a fixed shutdown date (finite horizon condition), which parallels the 2011 and, to some extent, also the more dynamic 2001 phaseout scenarios. The other simulated a constant probability of further operations (indefinite horizon condition). (See the Supplemental Material for more details on the method, hypotheses, and results.) In games with an indefinite time horizon, after each game period another period follows with some probability so that the players do not know how many times the games will repeat. In this context, unlike the situation in finitely repeated games, behavior based on rational self-interest can now coincide with socially desired behavior. As long as there is a substantial probability of future interaction and the probability of termination is low, people are predicted to refrain from exploiting others, and cooperation (or contribution to a public good) can be sustained. Our goal in Study 1 was to examine whether behavior in a scenario involving safety depends on endgame horizons. 
A total of 62 participants acted as managers of a hypothetical chemical plant. Operation of the plant could result-with a probability of $5 \%$-in a very costly accident. To avoid this accident, managers could invest in safety measures that kept the accident probability constant but carried costs. Alternatively, they could decide against investing in safety, thus incurring no costs, but the probability of an accident increased.

To examine the impact of a finite compared with an indefinite time horizon, we had half the managers make decisions knowing that the plant would be closed in 10 experimental years. For the other half, no definite closing time was specified. The game-theoretical predictions for the two time horizons are clear: In the finite horizon condition, there is a conflict between payoff maximization and safety investment; optimal payoff-maximizing behavior involves no investments after the third period of the game. In the indefinite horizon condition, safety investments are always the optimal and payoff-maximizing decision. (For additional details, see the Supplemental Material.)

The rationale behind these predictions is relatively simple: Investments in safety keep the probability of future accidents low, but when the future is limited-as in the finite horizon condition-keeping the probability of an accident low does not pay off. In contrast, because of the uncertainty about the length of the game in the indefinite horizon condition, the expected value of safety investments is always positive, making safety investment the payoff-maximizing choice. In both conditions, managers' investment choices largely followed the expected logic. As shown in Figure 2A, in the finite horizon condition, safety investments-as measured by the proportion of decisions intended to increase safety compared to all decisions-declined markedly as the shutdown of the plant approached. In the indefinite horizon condition, in contrast, the investments increased from the first to the sixth periods $(56 \%$ versus $71 \%$ ) and then remained constant.

We tested the robustness of Study 1's findings in a second study. In Study 2, we implemented
Figure 2. Proportion of yearly investments targeted to safety in (A) Study $1 \&$ (B) Study 2
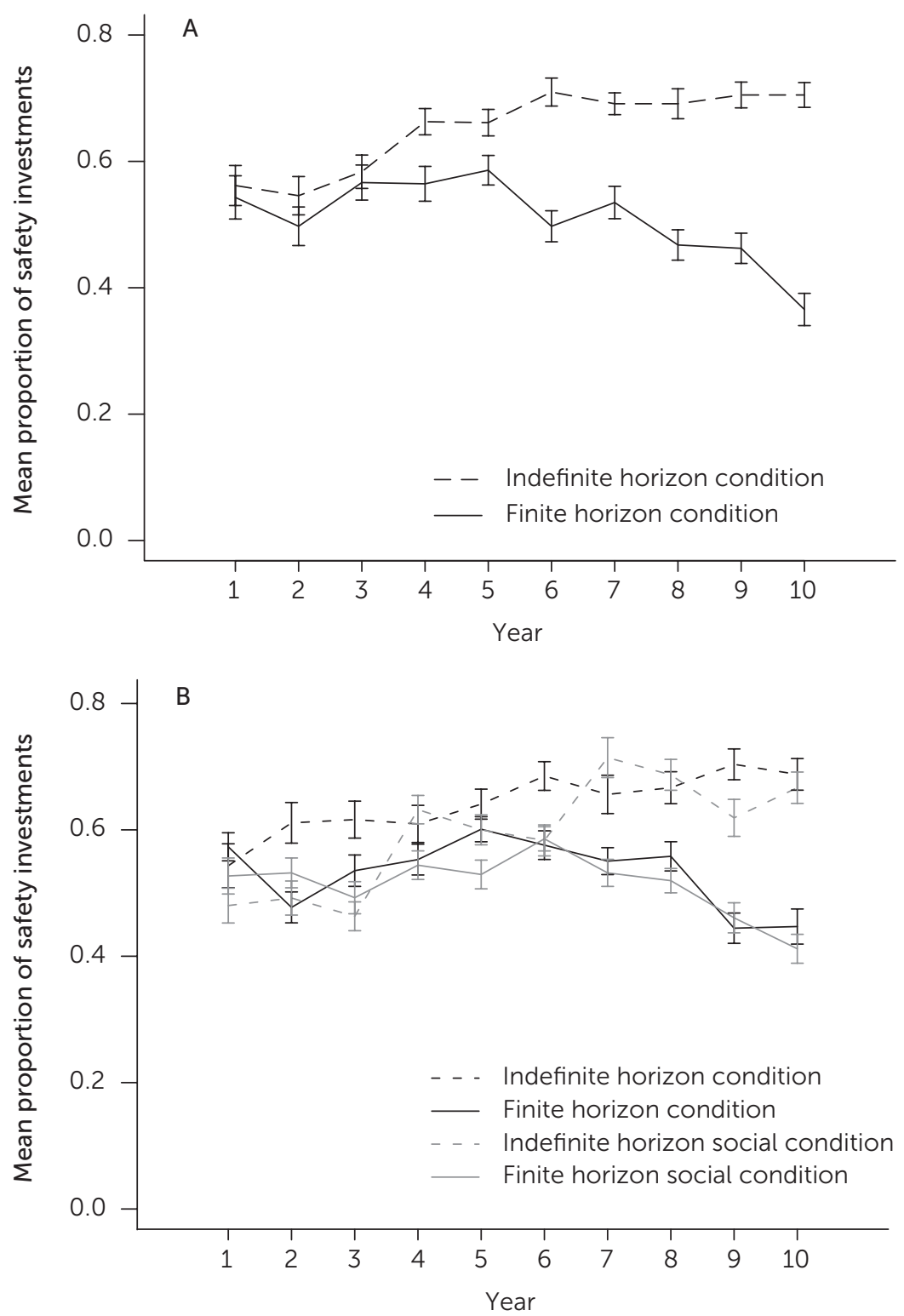

Note. The mean proportion of safety investments is the average number of investment choices intended to increase safety when compared with all decisions. Smaller proportions signify lower commitments to safety. Error bars represent an interval of \pm 1 standard error of the mean.

the same experimental paradigm and horizon manipulation but in addition tested whether imposing collective consequences for choosing not to invest in safety would alter behavior. Omitting safety investments not only affects people's own outcomes but can also have negative consequences for other people. We reasoned, therefore, that people with otherregarding social preferences might be motivated 
to choose the safety investment to avoid negative consequences for others.

In Study 2, a total of 427 participants were assigned to one of four experimental conditions. There were two social groups and two nonsocial groups, each with a finite or an indefinite horizon. We analyzed the behavior of only the 115 participants who demonstrated an understanding of the game by passing a knowledge test about it and who had not participated in more than 20 online surveys in the past month. Participants in the two social groups were informed that they would be randomly and anonymously grouped with three other participants in the experiment. If any member of that group was responsible for an accident's occurrence, the other three group members would also incur costs.

As Figure 2B shows, the findings of Study 1 were replicated, with declining proportions of safety investments in the finite but not the indefinite horizon condition. We had expected that participants in the social conditions would choose the safety investment option more often than would those in the corresponding nonsocial conditions, but we were wrong. The safety investment results did not differ substantially between the social and nonsocial conditions, and collective consequences did not prevent the observed endgame effect in the finite horizon condition.

In both studies, participants did not strictly follow the predictions of game theory: Those in the finite horizon condition did not completely stop investing in safety, and participants in the indefinite horizon condition did not always invest in safety. Nevertheless, the combined results demonstrate that a finite horizon triggered a declining investment in safety. An indefinite horizon, in contrast, resulted in a constant level of investments. Following the convention of experimental economics, players' outcomes depended on the other players' behavior in the social condition of the game, thus constituting a social interaction. It is, of course, conceivable that with additional face-to-face communication among players, the behavior could have turned out differently and might have led to more decisions to invest in safety than we saw.

\section{Discussion \& Conclusion}

Our goal was to conceptually, empirically, and experimentally explore the possibility that the phaseout policies of the German government are having unintended consequences for the safety of the country's nuclear power industry. Phaseout policies in Germany were put in place to increase public safety and, in the case of the 2011 decision, to respond to the shift in public risk perception after Fukushima. ${ }^{39,40}$

Our analyses highlight in different ways the potential risk of endgame behavior during the phaseout window of a dying industry. First, drawing on the public record, we chronicled the increasingly adversarial dynamics between the state and industry players tasked with maintaining high levels of safety in German nuclear power plants. Second, the analysis of reportable events after two phaseout decisions revealed mixed evidence for endgame behavior on the plant level. On the one hand, we found no increase of reportable events during the five years after the 2011 decision compared with the five years before. On the other hand, we found significantly higher average frequencies of reportable events during the five years after the 2001 decision than during the five years before the decision. Additionally, we found an increase in reportable events at the Barsebäck 2 reactor in Sweden shortly before its final shutdown. Third, the results of our two experimental studies show that endgame behavior occurs at the level of individual players in a finite-horizon scenario, even in scenarios where low safety investments can lead to negative consequences for other players.

Let us clearly emphasize that we have found mixed results and could not help but rely on small sample sizes for the plants' reportable events. Therefore, our conclusions are neither clear-cut nor very strong. Moreover, we were not able to reveal the reasons for the inconsistent findings. We tried repeatedly, persistently, and through various channels-but ultimately unsuccessfully - to get additional data about the plants, such as reports of near misses related to safety, data on personnel turnover, and statistics on occupational accidents or sick leave of plant personnel. In line with the abovementioned 
recommendations of the RSK, we advocate for more transparency about these and other figures that could help to indicate whether managers and employees of nuclear power plants are slipping into endgame behavior.

In light of the potentially disastrous consequences of declining safety in nuclear power plants, we believe that our analysis of the respective phaseout policies is important enough to warrant attention from policymakers, utilities, and the public. Even if the empirical evidence we provide is limited and mixed, the theoretical argument that endgame effects should be taken into account when creating phaseout policies appears important. For example, according to the German Atomic Energy Act (section 19a, paragraph 2), a plant is required to undergo a comprehensive safety review every 10 years, unless the plant is to be taken off the grid within the three years that follow what would be the next scheduled review. ${ }^{41}$ This means, for instance, that for the three plants that are scheduled to be shut down in 2022, the final comprehensive safety review occurred in 2009. One may question whether the waiver of an encompassing safety review is a wise decision in view of the potential endgame problems we have outlined; perhaps some version of the review should still be done. We, of course, hope that our concerns prove to be overly pessimistic. Nevertheless, we feel that an awareness of the risks embodied by endgame problems should intensify all stakeholders' efforts to prevent such an outcome-not only in Germany but also in other countries (such as Belgium and Switzerland) that have announced plans to phase out nuclear power.

The risks of endgame behavior deserve policymakers' attention because numerous factors may collude to amplify its potential impact. First, endgame behavior manifested as a shift toward self-interested behavior can occur across a hierarchy of levels, affecting the decisions of industry and policymakers, managers, and employees. The manifestation of endgame behavior is thus likely to be multidimensionalfrom employees showing increasingly rigid behavior, to the media vilifying employees of a dying industry (a risk highlighted by the RSK), ${ }^{21}$ "endgame behavior manifested as a shift toward self-interested behavior can occur across a hierarchy of
levels"

to the industry trying to absolve itself from any midterm or long-term liability for plants and radioactive waste. These dynamics are intensified by developments that are likely in a phaseout period even without endgame behavior, such as difficulties in recruiting new talent and retaining skilled staff at all levels (operators, regulators, technical support workers, and suppliers).

What are the possible responses to these risks? One strategy to reduce the risk of noncooperative endgame behavior related to safety would be to not give employees advance notification of a plant's shutdown. ${ }^{42}$ The results of the experimental studies suggest that endgame behavior is less likely to occur when the game has an indefinite time horizon. As long as the shutdown date is not known and unlikely to occur soon, endgame behavior should be less likely. Yet this strategy would be highly paternalistic and unfair to the employees and would be difficult to implement in an industry that faces strict and transparent termination dates. It would also pay little attention to the Swedish experience, which has highlighted the importance to safe operations of having transparent communication within the organization complemented by a monitoring system that attends to workers' psychological well-being (the "feeling of the workers"). ${ }^{43}$

A possible response to the industry's difficulties in recruiting new talent would be to establish innovative engineering programs focusing on the decommissioning and dismantling of aging nuclear power plants. Given that 234 operating reactors worldwide are more than 30 years old and, of those, 64 are more than 40 years old, ${ }^{44}$ there will be a fast-growing demand for this new and sophisticated expertise. Relatedly, 
the RSK has recommended implementing strategic competence management: a repertoire of measures with the goal of monitoring, maintaining, and further developing safetyrelevant competences among employees in the nuclear power industry. ${ }^{21}$ This approach also includes adopting measures (such as additional professional training and financial incentives) to counteract the ongoing loss of competence by fostering employees' commitment to their companies. At the same time, strategic competence management might also mean offering professional development and training in transferable skills to those employees who will inevitably have to transition to new careers in other industries, and perhaps even providing rewards for enrolling in the training.

Finally, on the level of public policymaking, decisionmakers need to recognize the challenge of designing and implementing phaseout policies that minimize the risk of endgame behavior. For instance, the Federal Council of Switzerland and the Swiss Parliament have decided to phase out nuclear energy gradually. Specifically, nuclear power plants will not be replaced once their operating lifetimes end. However, they can remain operational within their operating lifetime as long as their safety is guaranteed, that is, as long as a plant meets the statutory safety requirements. Such a phaseout policy provides a strong financial incentive to maintain and invest in high levels of safety and may thus be a more suitable way of keeping the risks of endgame behavior to a minimum-at least as long as some uncertainty remains regarding the onset of the decommissioning process.

\section{author affiliations}

Schöbel: University of Basel. Hertwig: Max Planck Institute for Human Development. Rieskamp: University of Basel. Corresponding author's e-mail: m.schoebel@unibas.ch.

\section{author note}

All authors contributed equally to the conduct of the experiments and the writing of the manuscript. We greatly appreciate the comments of Michael Baram and John S. Carroll on a previous version of the article. We thank Susannah Goss and Laura Wiles for editing the manuscript and Gilles Dutilh for preparing the figures. We also thank the Swedish Radiation Safety Authority for providing data on reported incidents in Swedish nuclear reactors.

\section{supplemental material}

- https://behavioralpolicy.org/publications/

- Methods \& Analysis

\section{endnote}

A. From the editors to nonscientists: For any given data set, the statistical test used depends on the number of data points and the type of measurement being used, such as proportions or means. The $p$ value of a statistical test is the probability of obtaining a result equal to or more extreme than would be observed merely by chance, assuming there are no true differences between groups under study (the null hypothesis). Researchers traditionally view $p<.05$ as statistically significant, with lower values indicating a stronger basis for rejecting the null hypothesis. The $W$ score is the minimum of the sum of positive or negative signed ranks; the smaller its value (with a minimum of 0 ), the less likely it is that the result occurred by chance (assuming the null hypothesis). 


\section{references}

1. Federal Ministry for the Environment, Nature Conservation and Nuclear Safety. (2002, February 1). Atomausstiegsgesetz nimmt letzte Hürde [Nuclear phase-out law takes the last hurdle; press release]. Retrieved from http://www.bmub.bund. de/presse/pressemitteilungen/pm/ artikel/atomausstiegsgesetz-nimmtletzte-huerde/

2. Federal Office for the Safety of Nuclear Waste Management. (2017). Laufzeiten deutscher Kernkraftwerke [Operating times of German nuclear power plants]. Retrieved from https://www.bfe. bund.de/DE/kt/kta-deutschland/kkw/ laufzeiten/laufzeiten.html

3. von Neumann, J., \& Morgenstern, O. (1944). Theory of games and economic behavior. Princeton, NJ: Princeton University Press.

4. Fudenberg, D., \& Tirole, J. (1991). Game theory. Cambridge, MA: MIT Press.

5. Auman, R. J., \& Maschler, R. (1995). Repeated games with incomplete information. Cambridge, MA: MIT Press.

6. Selten, R., \& Stoecker, R. (1986). End behaviour in sequences of finite prisoner's dilemma supergames: A learning theory approach. Journal of Economic Behavior \& Organization, 7, 47-70. doi:10.1016/0167-2681(86)90021-1

7. Roth, A. E., \& Murnighan, J. K. (1978). Equilibrium behavior and repeated play of the prisoner's dilemma. Journal of Mathematical Psychology, 17, 189-198. doi:10.1016/0022-2496(78)90030-5

8. Andreoni, J. (1988). Why free ride? Strategies and learning in public goods experiments. Journal of Public Economics, 37, 291-304. doi:10.1016/0047-2727(88)90043-6

9. Fehr, E., \& Gächter, S. (2002, January 10). Altruistic punishment in humans. Nature, 415, 137-140. doi:10.1038/415137a

10. Rasmussen, J. (1997). Risk management in a dynamic society: A modeling problem. Safety Science, 27, 183-213. doi:10.1016/s0925-7535(97)00052-0

11. Leveson, N. (2004). A new accident model for engineering safer systems. Safety Science, 42, 237-270. doi:10.1016/s0925-7535(03)00047-x

12. Leveson, N. (2011). Applying systems thinking to analyze and learn from events. Safety Science, 49, 55-64. doi:10.1016/j.ssci.2009.12.021

13. Gillis, J. (2014, September 13). Sun and wind alter global landscape, leaving utilities behind. The New York
Times. Retrieved from http://www. nytimes.com/2014/09/14/science/ earth/sun-and-wind-alter-germanlandscape-leaving-utilities-behind. html?_r=0

14. Dohmen, F., \& Hawranek, D. (2014, May 15). Bad banks for nuclear plants: Utilities look to German taxpayers. Spiegel Online. Retrieved from http:// www.spiegel.de/international/germany/ utility-companies-want-publictrust-for-winding-down-nuclearplants-a-969707.html

15. Commission to Review the Financing for the Phase-out of Nuclear Energy. (2016). Responsibility, safety and certainty-A new consensus on nuclear waste disposal: Final report of the Commission to Review the Financing for the Phase-out of Nuclear Energy. Retrieved from https://www.bmwi.de/ Redaktion/EN/Downloads/berichtexpertenkommission-kernenergie. pdf?__blob=publicationFile\& $v=2$

16. E.ON and E.OUT: A German powerproducer is breaking itself up to face the future. (2014, December 4). The Economist. Retrieved from http://www.economist.com/news/ business/21635503-german-powerproducer-breaking-itself-up-facefuture-eon-and-eout

17. Chazan, G. (2016, March 15). Eon and RWE sue German government over nuclear shutdown. Financial Times. Retrieved from http://www.ft.com/ $\mathrm{cms} / \mathrm{s} / 0 / \mathrm{df} 44 \mathrm{~d} 1$ ee-e792-11e5-bc31138df2ae9ee6.html\#axzz4IQTrXd9s

18. Rueter, G. (2016, December 6). Opinion: Limiting the greed of the nuclear industry. Retrieved from Deutsche Welle website: http://www.dw.com/ en/opinion-limiting-the-greed-of-thenuclear-industry/a-36664176

19. Hellemans, A. (2014, November 12). Vattenfall seeks $\$ 6$ billion in compensation for German nuclear phase-out. IEEE Spectrum. Retrieved from http://spectrum.ieee. org/energywise/energy/nuclear/ swedish-energy-giant-vattenfall-netsbillions-for-nuclear-phaseout

20. Reactor Safety Commission. (2012, July 12). Drohende Gefährdung der kerntechnischen Sicherheit durch Know-How- und Motivationsverlust [Potential threats to nuclear safety through loss of know-how and motivation; memorandum]. Retrieved from http://www.rskonline.de/sites/ default/files/reports/epanlagersk449hp. pdf
21. Reactor Safety Commission. (2016, November 3). Monitoring von Know-how- und Motivationsverlust und geeignete Maßnahmen zur Stärkung von Motivation und Know-how-Erhalt in der deutschen Kernenergiebranche [Monitoring of loss of know-how and motivation and suitable measures for strengthening motivation and preserving know-how in German nuclear power industries; statement]. Retrieved from http://www.rskonline. de/sites/default/files/reports/ epanlage1rsk488hp_0.pdf

22. Schönberger, A. (2017, January 31). Areva ist Geschichte [Areva is history]. Frankfurter Rundschau. Retrieved from http://www.fr.de/rhein-main/offenbachareva-ist-geschichte-a-743791

23. Kein Ergebnis: Gespräche über Lohnkürzung bei RWE [No result: Talks on wage cuts at RWE]. (2016, June 15). Kölnische Rundschau. Retrieved from http://www. rundschau-online.de/wirtschaft/ kein-ergebnis-gespraeche-ueberlohnkuerzung-bei-rwe-24232346

24. E.ON's nuclear unit to cut at least half its workforce by 2026. (2017, July 12). Retrieved from https://uk.reuters.com/article/ eon-nuclear-jobs-idUKL8N1K31YL

25. Dehmer, D. (2016, March 7). Wie sicher ist der Atomausstieg? [How safe is the nuclear phase-out?]. Der Tagesspiegel. Retrieved from http://www.tagesspiegel. de/politik/atomkraftwerke-wie-sicherist-der-atomausstieg-/13061456.html

26. Sommer, S. (2016, August 3). Kerntechniker in der Klemme [Nuclear engineers under pressure]. Frankfurter Allgemeine Zeitung. Retrieved from http://www.faz.net/ aktuell/beruf-chance/campus/machtder-atomausstieg-ein-kernenergiestudium-ueberfluessig-14362056.html

27. Probst, T. M., \& Brubaker, T. L. (2001). The effects of job insecurity on employee safety outcomes: Cross-sectional and longitudinal explorations. Journal of Occupational Health Psychology, 6, 139-159. doi:10.1037/1076-8998.6.2.139

28. Probst, T. M. (2004). Safety and insecurity: Exploring the moderating effect of organizational safety climate. Journal of Occupational Health Psychology, 9, 3-10. doi:10.1037/1076-8998.9.1.3 
29. Sutton, R. I. (1987). The process of organizational death: Disbanding and reconnecting. Administrative Science Quarterly, 32, 542-569. doi:10.2307/2392883

30. Weick, K., \& Sutcliffe, K. (2001). Managing the unexpected: Assuring high performance in an age of complexity. San Fransisco, CA: Jossey-Bass

31. International Nuclear Advisory Group. (1991). Safety culture (Safety Series No. 75-INSAG-4). Vienna, Austria: International Atomic Energy Agency.

32. Federal Office for the Safety of Nuclear Waste Management. (2016). Reporting procedure. Retrieved from http://www. bfe.bund.de/EN/ns/events/reportingprocedure/reporting-procedure_node. html

33. Ministry of the Environment. (1998). Sweden's first national report under the convention on nuclear safety: Swedish implementation of the obligations of the convention (Ds 1998:54). Retrieved from http://www.regeringen.se/49c6b3/ contentassets/625f71ce5da644549 043ffe124e44590convention-onnuclear-safety-ds-1998-54.pdf

34. Wiwen-Nilsson, T. (2006). Phasing-out of nuclear power in Sweden. Journal of Energy \& Natural Resources Law, 24, 355-361. doi:10.1080/02646811.2006. 11433441

35. Hansson, M., \& Wigblad, R. (2006) Pyrrhic victories-Anticipating the closedown effect. The International Journal of Human Resource Management, 17, 938-958. doi:10.1080/09585190600641255

36. Carroll, J. S. (1998). Organizational learning activities in highhazard industries: The logics underlying self-analysis. Journal of Management Studies, 35, 699-717. doi:10.1111/1467-6486.00116

37. Plott, C. R., \& Smith, V. L. (2008). Handbook of experimental economics results (Vol. 1). Amsterdam, the Netherlands: Elsevier.

38. Binmore, K., \& Klemperer, P. (2002). The biggest auction ever: The sale of the British 3G telecom licenses. The Economic Journal, 112(478), C74-C96. doi:10.1111/1468-0297.00020

39. Slovic, P. (1987, April 17). Perception of risk. Science, 236, 280-285. doi:10.1126/science.3563507

40. Roeser, S. (2011). Nuclear energy, risk, and emotions. Philosophy \& Technology, 24, 197-201. doi:10.1007/ s13347-011-0027-6
41. Federal Ministry for the Environment, Nature Conservation, Building and Nuclear Safety. (2016). Convention on Nuclear Safety: Report by the Government of the Federal Republic of Germany for the Seventh Review Meeting in March/ April 2017. Retrieved from https:// doris.bfs.de/jspui/bitstream/ urn:nbn:de:0221-2016100614132/1/ CNS_Bericht_2017_en_bf.pdf

42. Folger, R. (1993). Reactions to mistreatment at work. In J. K. Murnighan (Ed.), Social psychology in organizations: Advances in theory and research (pp. 161-183). Englewood Cliffs, NJ: Prentice Hall.

43. International Atomic Energy Agency (2003). Managing the early termination of operation of nuclear power plants (Safety Reports Series No. 31). Vienna, Austria: Author.

44. Schneider, M., \& Froggatt, A. (2017). World Nuclear Industry Status Report 2017. Mycle Schneider Consulting. Retrieved from https:// www.worldnuclearreport.org/IMG/ pdf/20170912wnisr2017-en-lr.pdf 